\title{
EL IDEARIO LITERARIO DE JOSÉ VASCONCELOS
}

(1916-1930)

En su participación en el homenaje a José Vasconcelos organizado por la UNAM en 1982, Enrique Krauze teminó su ponencia con esta frase: "Cuando, en 1929, Vasconcelos optó por vivir, México perdió a un santo laico, pero ganó una presencia más cercana y perdurable, más humana: la de un escritor'. Sin embargo, pensando en un trabajo que estoy preparando sobre las relaciones entre Vasconcelos y los miembros del grupo de los Contemporáneos, no quiero examinar aquí la obra literaria de Vasconcelos sino más bien sus ideas sobre la creación literaria.

Fn septiembre de 1921, en una entrevista con Esperanza Velázquez Bringas, José Vasconcelos se interroga sobre lo que él mismo llama, poniéndola en tela de juicio, su "vocación literaria". Confiesa que si escribe, lo hace por necesidad, a veces porque el debate nacional se lo exige, otras para exorcizar sus pasiones, pero siempre obedeciendo a un arranque interior, nunca por amor al oficio de escribir. En una conmovedora carta a Alfonso Reyes, del 7 de marzo de 1916, reconocía que tenía dificultades para pasar de la concepción a la redacción y comparaba su propio temple literario con el de Reyes: “ . . . creo que te será muy útil la preparación literaria que tu dedicación y las circunstancias te han impuesto. Porque para ti, como le decía Pedro [Henríquez Ureña] alguna vez, el obstáculo del estilo ya no existirá cuando escribas lo definitivo, al revés de lo que me pasará a mí, que ya me acostumbré a pensar y después no hallo cómo escribir", precisaba Vasconcelos y añadía que las "únicas cosas" que le interesaban eran "los valores del pensamiento, los valores no humanos, no célebres, no populares, no académicos,

1 Esperanza Velázquez Bringas, Pensadores y artistas, Cultura, México, 1922 , p. 17. 
el fondo, la esencia del pensamiento de los hombres más avanzados espiritualmente"; y en la misma carta se preguntaba, adelantándose a un debate acalorado que tomará toda su amplitud con los Contemporáneos, "si . . no podemos más que seguir las huellas de la que es nuestra raza, y si por lo mismo nos está vedado pensar umiversalmente"2. En septiembre del mismo año, al evocar en una nueva carta a Reyes su ensayo titulado "La sinfonía como forma literaria',3, confiesa a su antiguo compañero del Ateneo de la Juventud: "Renuncio a la esperanza de que suene bien, me conformo con que se entienda"' Como siempre, Alfonso Reyes tomará en serio la función de mentor literario que le confiere Vasconcelos, y en abril de 1920 le da una serie de consejos y le asesta algunos reparos:

I ${ }^{\circ}$ Procura ser más claro en la definición de tus ideas filosóficas: a veces sólo hablas a medias. Ponte por encima de ti mismo: léete objetivamente, no te dejes arrastrar ni envolver por el curso de tus pensamientos. Para escribir hay que pensar con las manos también, no sólo con la cabeza y el corazón. $2^{\circ}$ Pon en orden sucesivo tus ideas: no las incrustes la una con la otra. Hay párrafos tuyos que son confusos a fuerza de tratar de cosas totalmente distintas, y que ni siquiera aparecen en serio.

Como para mitigar un poco la aspereza de esas observaciones, Reyes reconoce que debe a los libros de Vasconcelos "emociones muy intensas, de un orden seguramente superior a lo puramente literario"."5.

Con cierta lucidez, Vasconcelos admite que no tenía dotes para la creación literaria propiamente dicha, lo que comprueban sus desafortunadas incursiones en el teatro o los versículos algo grandilocuentes de los Himnos breves publicados en la revista México Moderno ${ }^{6}$, pero lo que desmienten sus cuentos de La sonata mágica $\mathrm{u}$, obviamente, los primeros dos tomos de sus Memorias,

${ }^{2}$ Carta desde Nueva York a Alfonso Reyes. Capilla Afonsina.

${ }^{3}$ Incluido después en El monismo estético. Cf. J. Vasconcelos, Obras completas, Libreros Mexicanos Unidos, México, 1961, t. 4, pp. 20-40. Todas las citas corresponden a esta edición (las fechas varían en los diferentes tomos: t. 1: 1957 ; t. $2: 1958 ;$ t. $3: 1960$; y t. $4: 1961$ ).

${ }^{4}$ Carta del 6 de septiembre de 1916. Capilla Alfonsina.

${ }^{5}$ Carta de Reyes a Vasconcelos, del 23 de abril de 1920. Capilla Alfonsina.

${ }^{6}$ J. Vasconcelos, "Himnos breves", México Moderno, agosto de 1920, núm. 1, 1-4. 
Ulises criollo y La tormenta. En una miscelánea publicada en 1919 con el título de Divagaciones literarias y reeditada en $1920^{7}$, Vasconcelos incluye un artículo algo raro, titulado "Libros que leo sentado y libros que leo de pie", donde establece una taxonomía de los libros en función de la emoción que suscitan en el lector'. Los que lee "de pie" son: "la Tragedia Griega, Platón, la Filosofía Indostánica, los Evangelios, Dante, Espinoza, Kant, Schopenhauer, la música de Beethoven, y otros, si más modestos, no menos raros". Podríamos añadir a Plotino, Romain Rolland y Tolstoi. Dejemos de lado esta lectura "emocional" que le parecerá a Jorge Cuesta el colmo de la abominación, y fijémonos en otros aspectos más problemáticos del artículo: la afirmación de la vocacion catánica y "disidente" de la hteratura ("escribir libros es un triste consuelo de la no adaptación a la vida"), la concepción de la escritura como acto de rebelión ("un libro noble siempre es fruto de desilusión y signo de protesta") y también despunta esta idea que Vasconcelos desarrollará más tarde en su ensayo de 1926, Indología, donde esfuerza, dice, su "pobre voz de filósofo metido a caudillo" ": la vocación literaria estriba en una formación, en la adquisición de un "bagaje literario" - la expresión se encuentra también en Ulises Criollo-, en la integración de una cultura necesariamente "universal" —hasta aquí encontramos unas conexiones evidentes con las teorías de los Contemporáneos - lo que a su vez - y aquí, sí, hay una verdadera discrepancia generacional- confiere al intelectual un estatuto de "profeta", de "inspirado", de "sacerdote de la religión de lo absoluto", de "Mesías", de "Hermes americano" ("somos tan pocos en América los que escribimos que no se pierde una línea"10). Hasta este extremo no se atreverá a ir la generación siguiente ni la de los Contemporáneos.

Las reservas que periódicamente formulaba Vasconcelos respecto de sus propias aptitudes para la escritura y sobre el "arte de escribir" en general, no le impidieron consagrar uno de los

7 J. Vasconcelos, Divagaciones literarias, Murguía, México, 1919. (2a ed.: Edit. América Latina, México, 1920.) Contiene: "Libros que leo sentado y libros que leo de pie", "Recuerdos de Lima, nocturno", "El fusilado, cuento mexicano", "Visiones californianas: Ensenada, San Diego, Los Angeles, San Francisco", "Los signos".

${ }^{8} \mathrm{~J}$. VASCONCELOS, "Libros que leo sentado y libros que leo de pie", en Obras completas, t. 1, pp. 81-83.

9 J. Vasconcelos, Indología, Obras completas, t. 2, p. 1103.

${ }^{10}$ Ibid., p. 1107 
ensayos de El monismo estético (1918) a una reflexión sobre las condiciones de la creación literaria. Esta reflexión se nutre con algunos estudios de Alfonso Reyes, reunidos en una compilación publicada en 1911, Cuestiones estéticas ${ }^{11}$. A partir de las teorías estéticas de Benedetto Croce y de los escritos de Mallarmé, Reyes se preguntaba si era posible escribir (y también pintar, componer música, hacer escultura) prescindiendo de todo referente anterior y de los "registros arbitrarios de la escritura". Algunos escritores habían buscado la respuesta en el ámbito de la filosofía, concentrándose en los procesos del conocimiento, y otros se habían dedicado preferentemente a analizar el nacimiento y desarrollo de la emoción estética: es esta segunda vía la que parece elegir Vasconcelos. Para keyes, tal enfoque conlleva el riesgo de desembocar en una especie de formalismo: "El estético teórico - escribe Reyes- busca las leyes según las cuales sienten los hombres la belleza; pero si el poeta quiere seguirlo, hará, invariablemente, obra de mera ingeniosidad, cuando no de «retórica»". Este tipo de literatura, que Reyes califica de "tendenciosa", habla más al espíritu que al corazón, y no consigue su objetivo fundamental, que consiste en descubrir su autonomía expresiva, fuera de toda "imitación": "La literatura que predica el bien - reitera Reyes-, o busca sistemáticamente la verdad, o se empeña en realizar el concepto teórico de la belleza propuesto por las filosofías, y con los mismos procedimientos que éstas le proponen, es, indudablemente, literatura tendenciosa',12.

A pesar de una lectura atenta de los artículos de Reyes, Vasconcelos supeditará siempre la escritura a la idea o a la emoción, sin encontrar para su obra un tono verdaderamente personal, con la excepción, desde luego, de las Memorias. Por eso, los escritos de Vasconcelos adolecerán con frecuencia de esta "retórica" y de ese "formalismo" denunciados por Reyes. Por otra parte, Vasconcelos comparte algunas sugerencias contenidas en una conferencia pronunciada por Reyes en enero de 1910, dentro del marco del Ateneo de la Juventud y consagrada a la estética de Góngora. Reyes postulaba que de la poesía de Góngora brotaba esa "noble virtud" del lirismo que libera el alma, arrancándola a las concreciones del razonamiento y de las pesadas dialécticas;

11 A. ReYes, Cuestiones estéticas, Sociedad de Ediciones Literarias y Artísticas, París, 1911.

${ }^{12}$ A. Reyes, "Sobre el procedimiento ideológico de Stéphane Mallarmé", Cuestiones estéticas, en Obras completas, F.C.E., México, 1955, t. 1, p. 97. 
de tal poesía emana un impulso lírico que tiende a "fundir" imágenes y ritmos en algo trascendente ${ }^{13}$. Es esta evocación de un posible poder catártico de la literatura lo que sedujo a Vasconcelos, que intenta infundirlo en sus propios escritos y lo recomienda a sus compatriotas.

En su ensayo titulado "La sinfonía como forma literaria", afirma que la literatura, al igual que el arte, debe expresar "el ideal confuso, inmortal, infinito"; debe "decir" lo indecible, expresar lo inefable, esclarecer lo insondable. Volviendo a la fuente misma del acto literario, Vasconcelos considera que el len. guaje cumple una "función estética", al igual que "el sonido del músico, el mármol del escultor"; dentro de los distintos géneros - el drama, la cpopeya, el diálogo y el discurso-, el "estilo literario" cumple esa función. Como muchos escritores mexicanos e hispanoamericanos de aquella época se interroga sobre la emergencia de un género literario perfecto. El discurso, destinado a convencer mediante procedimientos dialécticos, aparece como una "desviación" estética, lo cual permite a Vasconcelos oponer la "expresión", que obedece a leyes estéticas, y la "demostración" sometida a la argumentación lógica. Sólo la primera es verdaderamente "creadora" en la medida en que refleja los impulsos del yo profundo, que hace accesibles a otras conciencias. Es en la poesía y la música donde la expresión estética es la más directa, porque se sitúa en las fuentes mismas de la creación, mientras que en el discurso le es posterior.

Durante largo tiempo la expresión escrita ha obedecido a los imperativos de racionalidad propios del discurso o de esa organización de varios discursos llamada tratado. Según Vasconcelos, esta forma filosófica, "sintética y acabada", destinada a introducir orden y coherencia en el contexto humano, ha influido, en cierta época, las producciones literarias y artísticas: los mejores ejemplos de ello son la Divina comedia de Dante, la Ética de Spinoza y la sinfonía clásica anterior a Beethoven. El tratado tiene ambiciones epistemológicas y dogmáticas que cobraron nuevo vigor y nueva actualidad con el triunfo de las disciplinas científicas, tanto como tal, o tanto en su forma más modesta: el ensayo. Vasconcelos, que abordó tal género con el Pitágoras, cuya primera edición se publica en La Habana en 1916, lo juzga con severidad: "Bajo el nombre de ensayo se populariza un género fácil, brioso, ágil, libre. Podrá no ser completo, y ni siquiera aspira a ser-

13 A. Reyes, "Sobre la estética de Góngora", Cuestiones estéticas, pp. 61-85. 
lo; no observa reglas ni pretende crearlas; ofrece sus vuelos flexibles a los atrevidos, y satisface ampliamente a los incompletos, a los espíritus no absolutos que se conforman con los vislumbres de verdad sin exigir sistemas que la contengan por entero" 14 ¿Puede considerarse al ensayo como una simple "derivación menor" del tratado, o bien es la manifestación de un género literario nuevo? Para Vasconcelos, sólo puede ser un "género transitorio" del que hay que liberarse, ya que marca, según él, una tendencia de la época que prefiere el brío a la profundidad, lo parcial a lo universal, la sonoridad a la idea, la dispersión al "monismo". Su única ventaja es su flexibilidad y la libertad relativa que deja al escritor: para algunos, representa "una especie de protestantismo literario, una rebelión contra el romanismo de la inteligencia"; para Vasconcelos, a veces está "viciado de mediocridad", porque es "desenfrenadamente personal". Por tanto se interroga sobre si existirá una vía nueva y fértil entre la rigidez del tratado y la superficialidad del ensayo.

En su intento de definir este " nuevo género literario", Vasconcelos tiene que abordar el tema de las propiedades del lenguaje. El artista debe plegarlo a "los arrebatos líricos de la intuición creadora", sin quitarle nada de su "energía" ni de su "sentido profundo". Dado que el impulso creador es individual y variable, cada artista debe descubrir su propio campo de acción y su estilo, evitando mostrarse demasiado respetuoso de las formas y los géneros consagrados. A menudo son los poetas quienes indican el camino a seguir devolviéndole al espíritu su iniciativa, descubriendo nuevos ritmos y sonoridades inéditas, rompiendo ese "formalismo" que géneros demasiado retóricos, como el tratado o el ensayo, habían impuesto (y del cual el mismo Vasconcelos no supo siempre escapar).

${ }^{14}$ J. VASCONCElos, "La sinfonía como forma literaria", Obras completas, t. 4, p. 23. En una carta a Reyes del 12 de agosto de 1916, Vasconcelos escribe: "estoy trabajando en un ensayo sobre "la sinfonía como forma literaria", en el cual sostengo que no es el tratado ni tampoco el ensayo la forma ideal del libro, sino que ha de desarrollarse un nuevo género, el género sinfónico a imitación de la música y construido ya no con la lógica del silogismo sino con la lógica de la música; es decir de acuerdo con la ley estética. En esto aprovecho mi teoría del impulso y pongo como ejemplos del futuro género: el Zaratustra de Nietzsche, las Eneadas de Plotino, todas aquellas obras que no obedecen a plan dialéctico sino a orientaciones y trabazón de mera afinidad estética". Capilla Alfonsina. 
En marzo de 1921, en el texto de presentación de la revista El Maestro - en la que participan, recuerdo, José Gorostiza, Bernardo Ortiz de Montellano, Carlos Pellicer, Jaime Torres Bodet-, Vasconcelos se rebela nuevamente contra toda fidelidad esterilizante a las "normas", que, además, con frecuencia se inspira en modas literarias importadas del extranjero. Aquí también aparece otra discrepancia fundamental que crea, en realidad, un verdadero foso generacional: más allá de las modas, Vasconcelos desconfía de la "contemporaneidad", de la actualidad literaria y cultural de su época, si se exceptúa la obra de Romain Rolland, en cuya producción admira sobre todo las biografías de los hombres ilustres. Hay que volver al "canto mixto" - prosa y música- de la antigüedad, de donde se derivan la lírica, la tragedia y la música moderna. En la tragedia, en particu. lar, "lo poético, despersonalizado, sigue leyes ajenas a la lógica, incontenibles dentro del tratado. La tragedia intensifica la vivacidad, la frescura, la emoción de la lírica; y por encima del anárquico vivir, más allá de los dolores y la esperanza, impone ley y hado misterioso, propiamente estético". Lejos de las frivolidades y las modas pasajeras, la revista El Maestro intentará que se capte la belleza en su perennidad, con el fin de alcanzar esa comunión de los hombres en el impulso estético que era ya un elemento central de El monismo estético. El objetivo que la revista persigue es, pues, doble: por un lado, aportará al más amplio público posible conocimientos prácticos y concretos, tendientes a una mejor inserción de los hombres en la sociedad; por otro, indicará a los autores la senda de la humildad y la simplicidad, y los mantendrá apartados de toda "vana literatura" y de la "ironía mordaz y destructiva" que con demasiada frecuencia se acepta como moneda corriente en los medios intelectuales, "hábiles para la censura, pero inútiles para la obra”. Ya es hora de que escapen al imperialismo aplastante de los tabúes mundanos:

El intelectual de oficio no se atreve siquiera a escribir si no reviste su pensamiento con todos los primores mediocres de su estilo convencional, y nada le importa que su corazón calle ante las necesidades públicas, que la pasión sofoque sus arrebatos más nobles, con tal de arrancar un aplauso ruidoso y unánime del coro inmortal de los necios ${ }^{15}$.

15 J. Vasconcelos, "Un llamado cordial", El Maestro, abril de 1921, núm. 1, 5-10. 
Para Vasconcelos, la poesía es un arte cuyos efectos son necesariamente limitados en el tiempo, y su alcance es menor que el de la prosa, donde el verbo creador puede encarnarse en ideas, emociones, intuiciones, exploraciones ${ }^{16}$. Sin embargo, se nota en él una verdadera fascinación por la poesía - siguiendo en eso la tradición modernista - y da, por ejemplo, un sitio de honor a quien considera "el más alto, el más inspirado de los poetas del mundo": Dante Alighieri. Con motivo de la conmemoración, en noviembre de 1921, del sexto centenario de la muerte del poeta, Vasconcelos pronuncia un largo discurso en el que sostiene que "la voz del Dante es una de esas voces que proclaman y confirman verdades eternas'. En la época contemporánea, se considera a Dante corno "vidente y apóstol, y por lo mismo superior al genio: más que flósofo y más que poeta, huminado. Lra cl uno de aquellos para quienes la vida es tragedia; tragedia mas no desastre: transfiguración que produce valores eternos" 17. Más allá de estas fórmulas algo huecas y rimbombantes, se nota de vez en cuando, en sus ensayos y artículos, una verdadera sensibilidad poética y un enfoque más original, como cuando en Indologia hace una breve comparación entre la obra de Walt Whitman y la de Rubén Dario ${ }^{18}$, cuando exalta a la vez el compromiso intelectual y la espontaneidad poética de Gabriela Mistrali9, cuando glosa el ritmo trascendental y la música interior de Rabindranath Tagore, a cuya obra llega a través de un comentario bastante fino de Serafita, la novela de Balzac ${ }^{20}$, o cuando

${ }^{16}$ Más tarde, en su Estética, calificará a la poesía de "juego artificial y artificioso", Obras completas, t. 3, p. 1690.

${ }^{17} \mathrm{~J}$. Vasconchios, "Discurso en el VI centenario de la muerte de Dante Alighieri", Boletín de la Universidad, 1921, núm. 7, 267-283.

${ }^{18} \mathrm{~J}$. VAsconcelos, Obras completas, t. 2, pp 1212-1213. Haciendo una comparación entre la colonización de Estados Unidos y la de América Latina, Vasconcelos comenta: "Allí la tarea consistió en ponerse a ligar la conciencia con la naturaleza vacía; entre nosotros la conciencia se encuentra en un espacio lleno de presencias milenarias". Esta oposición se manifiesta cuando se compara la obra de Walt Whitman con la de Rubén Darío: "Si comparamos el abrazo diomsíaco, la profunda y masculina compenetración de Walt Whitman con su naturaleza; si la cotejamos con los fulgores dispersos, con el atisbo cósmico de Rubén Darío, tendremos que reconocer que con ser tan grande nuestro poeta se murió sin escribir el poema del continente".

${ }^{19}$ J. Vasconcelos, "Carta de Gabriela Mistral", Repertorio Americano, noviembre de 1992, núm. 9, 113-114.

${ }^{20} \mathrm{~J}$. Vasconcelos, "El apóstol", La Antorcha, enero de 1925, núm. 14, p. 4: "La América Latina, que hasta hoy sólo podía contar con certeza con dos genios auténticos, la Ibarbourou y la Mistral, se encuentra en estos ins- 
comenta, en un artículo mandado en 1928 a la revista colombiana Lecturas Dominicales y totalmente ausente de su hemerografía repertoriada, los Versos sencillos de José Martí en la edición de sus Obras completas preparada y publicada en París (1926) por Armando Godoy y Ventura García Calderón ${ }^{21}$.

Hay en Vasconcelos un rechazo permanente de lo que él llama la "mediocridad", de lo circunstancial y "mundano" en la obra literaria, de cualquier supeditación o función "ancilar" de la literatura, para decirlo con palabras de Alfonso Reyes, de este "diletantismo sobrio y frío" que denunciaba Jaime Torres Bodet en un artículo roborativo de México Moderno dedicado a Anatole France $^{22}$. Lo fascina el encontronazo de las ideas en el período que le toca vivir y confesa senchlamente a Esperanza Velázuez Bringas que lamenta no tener el talento de "encamar" esos conMictos ideológicos en personajes de ficción, como pudieron hacerlo Ibsen o Romain Rolland con su Jean-Christophe ${ }^{23}$, y reconcoe implícitamente el fracaso de su obra teatral Prometeo vencedor (1920), presentada como una larga meditación filosófica dialogada, entrecortada por las intervenciones de bailarines y coristas que encarnan el poder del instinto vital y las oscuras fuerzas "dionisíacas", donde Vasconcelos había vertido lo esencial de sus interrogantes sobre el conflicto entre las leyes de la naturaleza y las del espíritu, sobre la soledad fundamental de todos los grandes reformadores, sobre la necesaria abolición de cualquier forma de tiranía, sobre la inmortalidad y el cambio, sobre las dicotomías simbólicas sombra/luz, vida/muerte, espíritu/mate ria, y sobre la "fecundidad" del sufrimicnro". A su vez, los

tantes honrada por el genio de un apóstol, que es probablemente la figura más grande del mundo contemporáneo. Rabindranath Tagore es grande porque es un prodigioso artista, un poeta a la hindú, para quien el verso es canción, y el ritmo del pensamiento es el mismo de la música".

${ }^{21} \mathrm{~J}$. VAsconcelos, "El genio en Ibero-América", reproducido en Repertorio Americano, julio de 1928, núm. 1, 8-9 y julio de 1928, núm. 2, 21-22. Comentando el poema "Flores del cielo" de Versos libres, Vasconcelos concluye así su artículo: "No se concibe una condenación más firme y más hermosa de esa poesía literaria que llena las épocas de decadencia y mayor valor alcanza en labios que podían divertirse haciéndola. Al alcance de su virtuosismo pero muy abajo de su gran alma. Con razón Gabriela Mistral, cada vez que piensa en Martí, dice: "Era el ángel»; en efecto, una naturaleza de arcángel".

${ }^{22} \mathrm{~J}$. Torres Bonet, "Letras francesas: Anatole France", México Moderno, octubre de 1920, núm. 3, 184-185.

${ }^{23}$ E. VelázQuez Bringas, op. cit., pp. 17-18.

${ }^{24} \mathrm{~J}$. Vasconcelos, Prometeo vencedor. Tragedia moderna en un prótogo y tres 
Contemporáneos acudirán en su teatro a la veta mitológica; Vasconcelos les había facilitado el acceso a las tragedias de Eurípides o de Esquilo, en las ediciones de los Clásicos preparadas y supervisadas por Julio Torri; pero ellos prefirieron releer la mitología a la luz algo lúdica y a veces paródica de las obras teatrales de Jean Cocteau o de Jean Giraudoux. Y si el teatro y ciertos ensayos deVasconcelos recuerdan el unanimismo de Jules Romains, será más bien Knock (1923) o Donogoo (1930), donde detrás de la carnavalización del discurso se disfrazan debates muy serios sobre la medicina o la ciencia, lo que atraerá a los Contemporáneos.

Pese a su evidente voluntad de renovar y actualizar "los grandes mitos trágicos" de que hablaba Nietzsche, los dialogos del teatro de Vasconcelos se reducen a una larga serie de monólogos yuxtapuestos, que no logran liberarse de una base "filosófica" que los hace abstractos y pesados. A diferencia de Lunatcharsky -en quien el futuro ministro de Obregón se inspira en parte para sus reformas educacionales-, Vasconcelos no es un verdadero dramaturgo, y no pudo dar al teatro mexicano textos capaces de poner en práctica sus ideas fructíferas e innovadoras sobre el arte dramático. Ideas que, sin embargo, encontraron cierto eco entre los Contemporáneos, aunque sea eco contradictorio, como lo señala brevemente Guillermo Sheridan en Los Contemporáneos, ayer ${ }^{25}$. En efecto hay en $V$ asconcelos un rechazo rotundo del teatro "burgués"; en El monismo estético, declara: "Destesto a Bernard Shaw y su palabrería de juglar; a France con su gracia afeminada y trivial; al dulce y conformista Barrie de las ternuras pequeñas"'26. Vasconcelos rechaza también el espacio cerrado y "la separación entre el teatro de análisis y la representación plástica" que Antonin Artaud condenará a su vez algunos años

actos, Lectura Selecta, México, 1920. Algunas semanas después de la publicación de su obra, Vasconcelos se queja amargamente de la incomprensión de los críticos. Escribe a Alfonso Reyes, el 16 de septiembre de 1920: "Muchos me han elogiado el primer acto del Prometeo; nadie me ha dicho una palabra del hondo drama posible que se desarrolla en el segundo acto y sólo Julio Torri me "ha sabido entender el tercero". Capilla Alfonsina.

${ }^{25}$ Guillermo Sheridan, Los Contemporáneos ayer, F.C.E., México, 1985, p. 350 .

${ }^{26}$ Ed. cit., p. 12. En una carta a Alfonso Reyes del 13 de mayo de 1918, Julio Torri escribe a propósito de Vasconcelos: "A Shaw lo llama el "pequeño esclavito celta". Todos los libros ingleses los encuentra mediocres y para uso de las clases egoístas y acomodadas. France le parece femenino. Etc.'. Capilla Alfonsina. 
más tarde, abogando como Vasconcelos por un "espectáculo total" 27. Quiere Vasconcelos "un escenario vasto como un coso", donde se desarrollen "dramas profundos" y "escenas de belleza deslumbradora", que procuren al espectador, en un primer momento, una sensación de "ahogo", para explotar luego "en ritmos de júbilo" 28 . La intensidad emocional y la penetración afectiva de los cantos y las danzas mexicanos integrados al espectáculo no harán sino crecer con "el progreso y el triunfo" de la comunidad nacional y continental. Con Nietzsche, Vasconcelos piensa que la grandeza de un teatro depende directamente de la dignidad moral, del nivel cultural del pueblo que lo engendra. Es reveladora del grado de civilización alcanzado por una nación.

Como primera etapa en la elaboración de este arte teatral nuevo, Vaconcelos quiere que se recurra a las manfestaciones más vigorosas del arte popular; hay que rehabilitar la música original de los sones tradicionales en el medio rural, así como el elegante vestuario de la provincia. Pretende en sus discursos y artículos que esta noción de "arte colectivo" sea ahora familiar al pueblo mexicano, como lo prueba el éxito de los "festivales al aire libre" organizados por la Secretaría de Educación Pública. Es pues necesario construir lugares apropiados para que el pueblo se reúna y, a través del canto, la música y la danza, se exprese, encuentre de nuevo "una voz y un ritmo". Por ello, el Estadio Nacional, inaugurado en mayo de 1924, "será cuna de nuevas artes; masas corales y bailes. Ni comedia, ni ópera; eso recuerda el horror del teatro urbano". Los nuevos hugares teatra" les se convertirán en reinos de la trascendencia: "Se oirá el recitado de grandes trágicas que conmueven sesenta mil almas con el calofrío de la palabra sublime. Se verán danzas colectivas, derroches de vida y amor, bailables patrióticos, religiosos ritos simbólicos, suntuosos, acompañados de músicas cósmicas". Será un espacio de creación; a la vez "escuela" y "templo", ofrecerá a las multitudes la posibilidad de "purificarse" y de "elevarse" al contacto con la belleza ${ }^{29}$. Ahora, lo más difícil quedaba por

27 Antonin Artaud, Le thêatre et son double, Gallimard, Paris, 1964, p. 132.

${ }^{28}$ Estas connotaciones de "ahogo" y de "júbilo", el reconocimiento de la preeminencia del teatro griego y la exhortación al advenimiento de un teatro "total" se derivan directamente de El nacimiento de la tragedia de Nietszche.

${ }^{29} \mathrm{~J}$. VASCONCELOS, "El teatro al aire libre de la Universidad Nacional", 
hacer: había que "alimentar" esa enorme maquinaria concebida para destilar belleza y trascendencia. $Y$ en este punto, Vasconcelos no propone nada, fuera de sus escasas y malogradas incursiones personales en el terreno del arte teatral.

Como Vasconcelos, Anatoli Lunatcharsky, en la misma época, también concebía la necesidad de un "teatro inmenso", en el que se pudiese ofrecer al público "espectáculos capaces de conmoverlo, de incitarlo a la risa, al entusiasmo o al desprecio". Pero el comisario del pueblo encargado de la Instrucción Pública también trazaba para el teatro una línea que $V$ asconcelos rechazaba: la del "realismo artístico", es decir, "un arte que observa la realidad circundante, la resume interpretándola, para luego

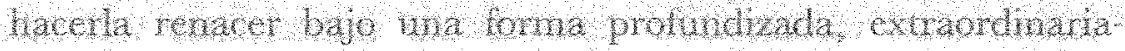
mente eficaz cono elemeato que puede contrbuir a lustarlo y a acelerar su progreso, imprimiéndole una dirección nueva"s: Habría que esperar algunos años para que el teatro mexicano, con Rodolfo Usigli, siguiera en parte tal orientación.

Tenemos para terminar que abordar el inmenso problema del nacionalismo, de la elaboración de una literatura nacional, en el que estarán profundamente implicados los Contemporáneos, como lo sabemos. ¿Cuál es la posición de Vasconcelos sobre el particular? A lo largo de su actuación como ministro y en muchas publicaciones, Vasconcelos se ha defendido rotundamente de hacer obra nacionalista. El discurso que pronuncia en Viena en diciembre de 1925 y que José Carlos Mariátegui reproduce en su revista Amauta bajo el título "El nacionalismo en la América latina"31 constimye una muestra bastante fiel de sus ideas en materia de nacionalismo. Hablando de la emergencia de una sensibilidad iberoamericana, Vasconcelos precisa:

Nuestra emoción particular tiene la ventaja de que es moderna y de que se está formando en una época en que el mundo ya no está limitado a las tradiciones y las capacidades de un solo pueblo. La civilización es ahora, por primera vez en la historia, un fenómeno

El Universal, 17 de febrero de 1922. Véase también la alocución pronunciada por Vasconcelos el día de la inauguración del Estadio (4 de mayo de 1924), en J. Vasconcelos, Discursos 1920-1950, Eds. Botas, México, 1950, pp. 115116.

30 A. V. Lunatcharsky, Théátre et révolution, Ed. François Maspero, Paris, 1971, p. 133.

${ }^{31} \mathrm{~J}$. VAsconcelos, "El nacionalismo en la América latina", Amauta (Lima), 4 de diciembre de 1926, 13-16, y 5 de enero de 1927, 22-24. 
realmente universal; no es inglesa, aunque los ingleses dominen materialmente el mundo; no es francesa, aunque los franceses extiendan su pensamiento a muchas naciones; no es alemana, no es italiana; no es ni siquiera europea porque hay muchas cosas fundamentales que Europa ha tenido que tomar de otras partes y todavía le quedan algunas que aprender. De suerte que por primera vez puede hoy afirmarse que la civilización comienza a ser mundial.

La creación literaria debe, pues, desarrollarse en función de esta perspectiva universal. Para Vasconcelos no hay ninguna contradicción ni aberración en, por ejemplo, un festival al aire libre que rewniera, como the el caso en mayo de 1922 , la representación de la Electra de Eurípides por la compañía española de Margarita Xirgú, la interpretación de Lohergrin de Wagner por la Orquesta Sinfónica Nacional, y la presentación de bailes regionales mexicanos por los niños de las escuelas de la capital. Tampoco la literatura debe encerrarse en una temática puramente nacional. En el plano de la cultura, es necesario ofrecer al pueblo una serie de "modelos" que tengan en cuenta, a la vez, su idiosincrasia y la aportación cultural universal: se fomenta la difusión de la canción y las danzas folclóricas, y se ofrece a los recién alfabetizados la oportunidad de leer a Dante y a Eurípides, lo que, como se sabe, no dejó de provocar un sinfín de polémicas. Por eso - y podemos encontrar aquí una vinculación estrecha con el programa literario y cultural de los Contemporáneos--, desde su discurso de inauguración del nuevo ministerio, Vasconcelos aboga claramente por lo que él mismo llama una "cultura sintética":

una verdadera cultura que sea el florecimiento de lo nativo dentro de un ambiente universal, la unión de nuestra alma con todas las vibraciones del universo en ritmo de júbilo semejante al de la música y con fusión tan alegre como la que vamos a experimentar dentro de breves instantes, cuando se liguen en nuestra conciencia los sones ingeruos del canto popular entonado por los millares de voces de los coros infantiles, y las profundas melodías de la música clásica revividas al conjuro de nuestra orquesta sinfónica. Lo popular y lo clásico unidos sin pasar por el puente de la mediocridad $^{32}$.

${ }^{32} \mathrm{~J}$. VAsconcelos, "Discurso inaugural del edificio de la Secretaría", en Obras completas, t. 2, p. 800. 
Vasconcelos comprendió pues la necesidad de dar una base "popular" y "nacional" a su política cultural, pero también fue partidario de inscribirla dentro de un marco "clásico" y "universal", con el fin de darle mayor alcance. Ahora bien, el referente "universal" de su política cultural y de su ideario literario remite más bien a la "cultura de las humanidades" que preconizaba Pedro Henríquez Ureña o al ámbito filosófico, con una preferencia por el pensamiento espiritualista. En materia editorial, por ejemplo, más que por una política de creación o innovación, el ministro de Educación optó deliberadamente por la divulgación de "libros de fondo", cuyo impacto sobre el público lector mexicano algunos juzgaron irrisorio. No tuvo la suerte, durante el corto período en que tuvo entre las manos la política cultural de México, de contar con un grupo de literatos dotados del talento, la madurez y la experiencia de un José Clemente Orozco o de un Diego Rivera, cuyo genio se había fraguado a la luz de los frescos de Giotto o Fra Angelico, y en un recorrido que lo lleva de Signac y Seurat a Cézanne, del Greco al cubismo de Braque y Picasso. A Vasconcelos mismo le faltó lo que, según Guillermo Sheridan, caracteriza y define la labor y el espíritu de los Contemporáneos: "el rigor crítico, el afán experimental, la voluntad de modernidad"33. Sin embargo, el Ministro de Obregón había sembrado una semilla que, a pesar de todos los obstáculos y de múltiples oposiciones, terminará por florecer. Como lo apunta Octavio Paz en El laberinto de la soledad, Vasconcelos basaba su sistema educacional y cultural en la tradición, pero una tradición vinculada con lo universal: "Nuestra tradición - comenta Pazsi de verdad estaba viva y no era una forma yerta, iba a redescubrirnos una tradición universal, en la que la nuestra se insertaba, prolongaba y justificaba'"34. 